\begin{tabular}{|l|l|}
\hline $\begin{array}{l}\text { EUROPEAN } \\
\text { PUBLIC SOCIAL } \\
\text { INNOVATION }\end{array}$ & $\begin{array}{l}\text { European Public \& Social Innovation Review (EPSIR), Vol 2 (1), 2017, ISSN 2529-9824 } \\
\text { E. Callorda Fossati, F. Degavre \& M. Nyssens. }\end{array}$ \\
& C Sinnergiak, Some Rights Reserved (cc) Er-NG-ND Creative Commons 4.0 International \\
\hline
\end{tabular}

\title{
HOW TO DEAL WITH AN "ESSENTIALLY CONTESTED CONCEPT" ON THE FIELD? SAMPLING SOCIAL INNOVATIONS THROUGH THE DELPHI METHOD ${ }^{1}$
}

Ela Callorda Fossati, Florence Degavre, Marthe Nyssens

University Catholique de Louvain

\section{KEY WORDS}

Social innovation

Essentially contested concept

Transdisciplinary research

Multiple-case study design

Sampling

Consensus-based methods

Delphi method

Eldercare

\begin{abstract}
How to select cases for multi-case analysis in social innovation research? This article addresses the practical issue of sampling units of analysis for further indepth study. This is a challenging methodological question since one recognizes the "essentially contested" character of the concept. Noticeably, the concept of social innovation generates endless disputes about its proper use. Theory on social innovation is controversial and fragmented, databases are generally not available, and pragmatism has its limits. Hence, conventional methods of sampling appear inadequate. As an alternative, we propose to adapt the consensus-based Delphi method in order to identify a pool of cases, sort them out and finally establish a sample. Our approach is fundamentally inductive and focuses on experts' perceptions of what is socially innovative. We demonstrate our argument using a transdisciplinary research project on social innovation in domiciliary eldercare as an example.
\end{abstract}

\section{Introduction}

This article addresses a specific methodological challenge in social innovation research: how to select cases for multi-case analysis? In other words, it deals with the practical question of sampling ${ }^{2}$ social innovation. Three connected reasons explain why this question deserves attention. First, knowledge on social innovation has been built to a large extent on case studies. This is understandable given the importance of contextual factors in innovation studies. Second, case study methodology clearly requires prior consideration of the type of cases that will be scrutinized. Third, and that point

\footnotetext{
${ }^{1}$ This article is based on the results of the WISDOM research project (Innovation sociale dans l'accompagnement à domicile en Wallonie) funded by the Walloon Region (DG06, Germaine Tillion program, 2014-2017) and coordinated by the authors. They would like to thank their colleagues and their partners for their active contribution to the project, the anonymous reviewers for their thoughtful comments on the paper and express their gratitude to Dr. Anna Safuta for her careful proofreading.

${ }^{2}$ Our sampling procedure differs from the logic referred to in probabilistic methods. Sampling here refers to the process of identifying (i.e. casing), sorting out and then selecting a certain number of units of analysis for further research through in-depth case studies.
} 
is at the core of our rationale, certain particularities of the social innovation concept do not allow for a straightforward adaptation of conventional methods of sampling. These particularities and the consequent difficulties in sampling are related to social innovation being an "essentially contested concept", as pointed out by Ayob and colleagues (2016). This question has not however been approached from a methodological point of view. In this article, we argue that as long as social innovation will remain a strongly ambiguous concept, consensus-based methods will remain a suitable method of sampling. We illustrate our claim by looking at a transdisciplinary research project on social innovation in domiciliary eldercare that used the Delphi method to select case studies. A transdisciplinary project involves researchers from various disciplines (in this case socioeconomics and public health) and stakeholders (here umbrella organisations of non-profit providers), considered partners in defining and implementing the research objectives (Byrne, Mullally, \& Sage, 2016; Popa, Guillermin, \& Dedeurwaerdere, 2015). Transdisciplinary research partnerships are based on a joint effort to produce knowledge, involving stakeholders in every stage of the research cycle ${ }^{3}$.

The article is divided into six sections. First, we examine social innovation from an epistemological perspective by framing it within the debate on contestedness in scientific research (Collier, Hidalgo, \& Maciuceanu, 2006; Gallie, 1956). Moreover, given that our research focuses on social innovation in domiciliary eldercare, we argue that current debates in this field are crucial to the selection of cases. Second, we discuss the inadequacy of conventional methods of sampling when applied to an essentially contested concept. Third, we introduce the Delphi method. This consensusbased method captures situated perceptions of what is socially innovative in a specific field, in a geographical context and for a selected group of actors. As such, it is suited for transdisciplinary research on social innovation. A fourth section explains how the Delphi method was adapted to the purpose of sampling and implemented in the context of a research on non-profit domiciliary eldercare. Fifth, we present an overview of the results of the sampling procedure by distinguishing three main steps: identifying, sorting out and selecting cases. The last section discusses the advantages and limitations of the proposed method.

\section{Social innovation as a contested concept}

Several critical assessments have pointed out the diverse and even conflicting meanings of social innovation. The concept has drastically evolved over time and embraces significantly different meanings across academic disciplines and schools of thought, but also among non-academic actors (including non-profit organisations, public authorities and businesses). Social innovation is thus clearly an essentially contested concept, as such concepts "inevitably involve endless disputes about their proper uses" (Ayob et al., 2016; Gallie, 1956, p. 169). In order to deal with such complex concepts and account for their contestedness, Gallie (1956) proposes an analytical framework comprising several interrelated criteria. Applied to the debate on social innovation, this framework is an effective way of informing the sampling procedure.

Appraisiveness. A common trait of recent definitions of social innovation is their strong normative aspect, namely their positive valuation (Ayob et al., 2016). This fulfils the criterion of appraisiveness, according to which contested concepts denote some kind of achievement (Gallie, 1956). As noted by Ayob and colleagues, the clearest illustration of the normative aspect of the social innovation concept is given by Pol and Ville (2009, p. 884): “An innovation is termed a social innovation if the implied new idea has the potential to improve either the quality or the quantity of life." Pol and Ville recognize that their definition does not really say what social innovation really is. Although they underscore its utility, they do not give further methodological advice. Another seminal

\footnotetext{
${ }^{3}$ Contrary to action research, which explicit aim is to transform social relations (e.g. to produce organizational change), the transdisciplinary research approach intends to improve the social relevance of knowledge production by the durable and coordinated collaboration between researchers with different disciplinary backgrounds and (other) social actors. Under that lenses, if change in the relation between science and society is expected to broadly impact social relations, that impact is not designed as such, and depends in fine on the reinforcement of capacities and on the autonomy of social actors.
} 
definition of social innovation defines it as: "innovations that are social both in their ends and in their means $[\ldots]$ that simultaneously meet social needs and create new social relationships or collaborations. In other words, they are innovations that are both good for society and enhance society's capacity to act." (Murray, Caulier-Grice, \& Mulgan, 2010, p. 3). The normative component of social innovation is also very clear here, notably in the last sentence. The problem with these definitions is that they omit the "dark side" of social innovation - i.e. risks, dangers, misuses, failures, resistances, oppositions, conflicts and oppressions involved in the innovation process (Larsson \& Brandsen, 2016).

Most definitions of social innovation encompass an analytical component. For example, the definition by Murray and colleagues quoted above refers to "social needs", "new social relationships" and "collaborations" and describes what social innovation really is, beyond its definition as a positive thing. Analytically, the literature on social innovation distinguishes two contradictory approaches of social innovation (Nyssens, 2015). Represented by Murray and colleagues, the "weak" approach stresses the newness, the social impact ${ }^{4}$, the role of for-profit enterprises as drivers of social innovation and the use of entrepreneurial and managerial methods. In the "strong" approach, social innovation is driven by local not-for-profit organisations, and hence, highlights the role of the social economy, its norms and values. However, that does not necessarily imply a homogenous approach of social innovation within the social economy.

Radical scholars associated with the "strong" approach, such as Moulaert (2009), have previously underlined the political nature of social innovation, a characteristic which probably explains why the normative and analytical components of the concept appear so intrinsically related. Moulaert (2009, p. 12) defines social innovation as "satisfaction of alienated human needs through the transformation of social relations: transformations which 'improve' the governance systems that $[\ldots]$ regulate the allocation of goods and services meant to satisfy those needs [...]. This means that social innovation involves [...] the transformation of social relations in space, the production of placebound and spatially exchanged identities and culture, and the establishment of place-based and scalerelated governance structures."

Internal complexity. A second criterion states that the "[valued] achievement must be of an internally complex character" (Gallie, 1956, p. 171). Confronted to internally complex concepts, researchers need to consider the possibility of disaggregation or, on the contrary, the strategic reasons why it makes sense to keep an integrative concept (Collier et al., 2006). In the field we focus in (domiciliary eldercare), scholars such as Giraud and colleagues (2014), follow the international debate on the long-term care reform in order to identify the most salient dimensions of social innovation. Accordingly, social innovation in domiciliary eldercare includes innovating in the areas of governance, service provision, quality of care, and participation.

Diverse describability. Relatedly, the criteria of diverse describability takes note of the fact that scholars (but also stakeholders) often focus on a single constituent of the contested concept and neglect its other dimensions (Collier et al., 2006). A recent systematic review of the literature on "innovations within eldercare" (Schultz, André, \& Sjøvold, 2015) noted that governance and participation aspects ("work environments" in their own terms) are seriously under-researched in the field.

Openness. A fourth criterion asserts that contested concepts are context-sensitive and open to periodic revisions that cannot be predicted (Collier et al., 2006; Gallie, 1956). Ayob and colleagues (2016) perfectly illustrate this criterion by showing the shifting importance of "social relations and technological innovation" within the social innovation field. Currently, domiciliary eldercare studies

\footnotetext{
${ }^{4}$ However, this first characteristic of the « weak » approach does not really apply to Murray and colleagues' definition, since they refer to "innovations that are social both in their ends and in their means". 
are increasingly interested in gerontechnologies and possible links with the so-called "silver economy" (Rialle, 2015).

Openness might also refer to the increased interest in the discursive analysis of social innovation (Evers \& Brandsen, 2016; Fougère, Segercrantz, \& Seeck, 2017; Giraud et al., 2014; Montgomery, 2016; Wittmayer et al., 2015). On the one hand, many authors understand the "weak" approach of social innovation as a neoliberal critique of the traditional welfare state. On the other hand, and probably more surprisingly, alternatives to the "weak" approach are described as a (Leftwing) libertarian critique (Giraud et al., 2014). Libertarian social innovations pursue governance without government; diversity in service provision; bottom-up and reflexive approaches to quality standards; and democratic modes of participation (Giraud et al. 2014). Some questions arise when the criterion of openness is translated to the domiciliary eldercare field: Do (Left-wing) libertarian and neoliberal critiques exhaust possibilities for critical approaches of domiciliary eldercare? Moreover, how does this discursive struggle translate into local debates surrounding social innovation?

Reciprocal recognition. According to this fifth criterion, actors using a contested concept recognise, at least partially, rival usages of the concept (Gallie, 1956). In social innovation research, literature reviews clearly acknowledge the existence of two opposed approaches. However, while the "strong" approach tends to argue explicitly against the "weak" approach, the latter takes advantage of its hegemonic status (Montgomery, 2016) to neglect alternative meanings.

Progressive competition. Finally, Gallie (1956) suggests that de-contestation is possible through progressive competition between opposing parties. Gallie's commentators are however sceptical about the virtues of conceptual disputes for improving the concept's definition (Collier et al., 2006).

Following Gallie's commentators, we assume that improvements in the scientific debate have more to do with transdisciplinary knowledge pointing to meaningful examples ${ }^{5}$ rather than with conceptual disputes alone. But which meaningful examples should be scrutinised? Any selection of social innovation cases needs to take into account the positive valuation aspect of the concept and more generally, the contribution to the scientific debate beyond current cleavages.

\section{The limits of conventional methods of sampling}

Multiple-case studies are a standard research method in social innovation research (Bouchard et al., 2015). As put by Hamel (1997, p. 10), case studies "relate an occurrence to its context and consider it under that lens [...] In other terms, [the case study method] deals with the question of how a [particular] context generates the occurrence [of the phenomenon] we are interested in". The multiple-case study approach is usually chosen over single case designs in order to examine how a phenomenon occur in different contexts (Stake, 2006). Multiple-case study designs are intensive inquiries into a relative small number of complex units, considered among a broader set of potential units (Seawright \& Gerring, 2008) ${ }^{6}$. As such, multiple-case designs are thus particularly suited to identifying contextual factors (when, where, by whom and how, etc.) contributing to the emergence and dynamics of social innovation. However, the social innovation literature usually does not reveal its sampling procedures and, most of all, how did these procedures make sense of the contestedness governing the scientific debate around the concept.

\footnotetext{
5 "Exemplars" is one of the Gallie's criteria. However, it was not discussed here in its own for two main reasons. First, Gallie recognizes than not all criteria are equally relevant for the examination of each essentially contested concept. Moreover, Gallie's commentators have strongly criticized that criteria at least in it narrow version, which states the existence of a single paradigmatic historical example (an exemplar) originally structuring the debate (like the French revolution in the conceptual debate on democracy) (Collier et al., 2006).

${ }^{6}$ The inquiry generally relies on qualitative methods but can also make use of quantitative methods. In the research project tanking here as an illustration, the empirical material collected principally consist on archives, interviews and focus groups. Nevertheless, we also conduct a quantitative survey on well-being at work. Clearly, at that stage the ultimate unit of analysis became the workers.
} 
Conventional sampling procedures usually refer to qualitative strategies or mixed methods approaches. Qualitative strategies are informed by theoretical choices and involve case selection based on researchers' expectations with regard to the potential knowledge input of each case. In other words, researchers rely on their intuition that selected cases are typical, extreme, paradigmatic, ensure maximum variation, etc. (Flyvbjerg, 2006; Stake, 2006). Mixed sampling procedures involve statistical assessments of the distribution of key variables among potential cases and allow for example estimations of what makes certain cases extreme (Seawright and Gerring 2008).

Mixed procedures are not adapted to social innovation research since the population of reference is unknown. There are no statistical or administrative categories corresponding to social innovation and thus no available datasets for assisting empirical research. The lack of an ad hoc dataset clearly differentiates social innovation research from innovation studies in economics, which are for the most part based on data recording patents filed by firms (Nagaoka, Motohashi, \& Goto, 2010). The few available exceptions ${ }^{7}$ are not relevant given the rationale of our research.

The problem with qualitative strategies is twofold. First, it leaves to the researcher the choice of the approach of social innovation. Out of the "weak" and the "strong" approaches should inform the selection of cases? Is there even a space for cases coming from the "weak" approach when the rationale of a research focuses on not-for-profit organisations as the main driver of social innovation? More fundamentally, what can be considered as a case of social innovation, and how does it relate to a broader set of potential units? The controversial and fragmented nature of social innovation theory complicates multiple-case studies and provides only partial and ambiguous answers to these questions.

A second problem with qualitative strategies is the extent to which they are based on pragmatic considerations. In fact, how to clarify expectations towards concrete cases? For example, how to ensure that selected cases represent maximal variation considering both the "weak" and the "strong" approaches of social innovation? Qualitative strategies require previous in-depth familiarity with the considered cases (Stake, 2006), which entails some risks. Familiarity might be correlated with easiness of access, the risk being then to rely on over-studied cases. Relatedly, there are also risks associated with relying exclusively on visible and hence probably successful cases. Focusing on success stories and leaving out less visible or less lucky innovations can contribute to a questionable standardisation of practices, a point addressed by Larsson and Brandsen in their ex-post critical account of the WILCO project on local urban social innovation in Europe. Remarkably, they refer to their sample as a "parade of successful innovations" (2016, p. 299). Each research team had to fix local cases by interpreting a set of previously defined selection criteria (Evers, Ewert, \& Brandsen, 2014) which were not devoid of bias towards success stories.

Are these pitfalls inevitable or could they be avoided? Certainly, pragmatic criteria alone are not sufficient to inform qualitative sampling in social innovation research. Researchers are placed in a very peculiar epistemological position, as they need to make sense of the contested character of the concept. Nevertheless, pragmatic criteria are still useful if explicitly accounted for and introduced as part of a broader methodological approach to sampling.

The following sections introduce the Delphi method as a relevant answer to the case selection issue in social innovation research.

\section{The principles of the Delphi method}

The Delphi method is frequently defined as a method for obtaining consensus within a group of experts whose expertise is consulted iteratively (Bourrée, Michel, \& Salmi, 2008). In more general

\footnotetext{
${ }^{7}$ Namely, the CRISES Database on Social Innovations (focusing on the large body of case studies produced in Québec) (Bouchard et al., 2015) or online repositories such as Ashoka or Innoserv used in the SIMPACT research project (Pelka \& Terstriep, 2016).
} 
terms, the method is characterized by structured communication within a group confronted with a complex problem (Linstone \& Turoff, 1975). In doing so, it puts to test a sort of capacity for collective human intelligence. The Delphi method is used to make decisions in situation of uncertainty, in fields where scientific studies are scarce or highly contradictory, and more generally when information is unavailable, too expensive to obtain, or when subjective inputs are at stake (Bourrée et al., 2008; Linstone \& Turoff, 1975). The contested nature of the social innovation concept is one such case involving highly contradictory studies, unavailable datasets and subjective perceptions, that the Delphi method can help address. Our argument is that the Delphi method is particularly suited to overcome sampling issues related to the strongly ambiguous nature of a concept. In this section, we start by explaining the notions of "expertise", "consensus", and "iterative consultation", which are central to the Delphi method.

The Delphi method requires identifying a series of "experts" on the issue under investigation. Delphi panels generally gather people with a professional expertise in the studied subject (Baker, Lovell, \& Harris, 2006; Fink, Kosecoff, Chassin, \& Brook, 1984). Rather than recruiting people with an official title, Goodman (1987) advocates choosing Delphi experts who are directly involved in what is at stake and have a good knowledge and field experience of the subject (be it from a practical, legal or managerial perspective).

The notion of consensus should not be understood as an unanimous agreement on every element under analysis (Bourrée et al., 2008). Rather, consensus in the Delphi approach involves considering each opinion at different moments (rounds) and following how opinions evolve as experts became aware of the opinions of others. The Delphi method supposes that sharing information through a structured communication process allows, to some extent, the canalization of experts' conflicting points of view. Murphy and colleagues (1998) notice that the Delphi approach usually results in a weak convergence of opinions and that the meaning of consensus is not always easy to interpret. For McKenna (1994) the method is useful to generate a debate rather than to generate a consensus. Or, as putted by Goodman (2017, p. 2), "conversation is not however the same as consensus". Additionally, the notion of consensus may vary according to the question under study, the size of the group of experts and its initial homogeneity, as well as the research timeframe.

In addition to expertise and consensus, the notion of iterative consultation (rounds) is crucial to the implementation of the Delphi method. Its three founding principles are controlled retroaction, non-confrontation between experts and opinion anonymization (Booto Ekionea \& Bernard, 2011; Dalkey, 1969). Controlled retroaction allows experts to position themselves simultaneously (but separately) with regard to the opinion formulated by others in the previous round. In other words, the results of each round are available to all the experts at the same time. The principles of nonconfrontation and anonymization aim to limit the influence of the group (namely the effect of leadership and self-censorship) on personal opinions. The Delphi method thus assumes there is a relation between power and knowledge construction. By neutralizing, at least partially and temporarily, power relations through a structured communication process, Delphi allows minority opinions to emerge. The following section shows how these principles were interpreted throughout the sampling procedure.

\section{Implementation of the Delphi method}

One of the great advantages of the Delphi method, and probably the reason why it is such as widespread research tool in a wide spectrum of disciplines, is its adaptability (Brady, 2015; Goodman, 2017; Landeta, Barrutia, \& Lertxundi, 2011). This applies in particular to the definition of expertise and consensus forming. This section explains how to adapt the Delphi method in order to meet the needs of a sampling procedure in a transdisciplinary research project on social innovation in domiciliary eldercare. 
The four distinct rounds of the process were conducted in collaboration with a support committee (table 1). The support committee was composed of three federations of home care services, a federation of community primary healthcare centres and an inter-sectorial federation advocating for non-profit organizations. The first task was to agree on an operational definition:

"A social innovation initiative is any initiative that seeks to address elderly people's aspiration for ageing in place. These initiatives focus on concrete needs emerging from this aspiration, be they expressed by the elderly themselves or by other stakeholders (paid professionals, volunteers or family or related caregivers)".

This definition centres on elderly people's aspirations and the notion of "ageing in place". Deliberately, participants were not given any additional elements on how ageing in place should be organised, financed or what should an ageing in place initiative look like. In that sense, this definition was meant to encourage the expression of a diverse range of initiatives. Only the not-for-profit nature of the initiatives and their regional settlement were constraining elements (imposed by the rationale of the research).

The support committee and the researchers identified a list of 51 experts to launch the Delphi process. We featured a wide variety of "professional expertise", as encouraged by the literature. The aim is to so-called consensual solution to light among a broad spectrum of possibilities (Murphy et al., 1998; Rowe \& Wright, 1991).

A different questionnaire was sent out to the experts in the first and second round of Delphi. On the basis of the definition above and following a mixed approach combining open and closed questions (Tapio, Paloniemi, Varho, \& Vinnari, 2011), experts were asked in round 1 to identify up to a maximum of three initiatives and explain what made them innovative (open question) and social (items referring to norms and values). 42 initiatives were identified. The questionnaire in round 2 included the list of previously identified initiatives with a short description of each of them. Experts had to identify the cases they knew and, among them, to shortlist three that they considered the most socially innovative. Additional (open and closed) questions were asked relating to this "Top 3" in order to clarify experts' perception of a social innovation. At the end of this second round, the information on the 42 cases was compiled in a catalogue that would inform the following rounds.

The third round consisted of a restricted panel of experts. This adaptation of the method was not only a matter of simplicity. It can be problematic to give each expert a voice on a decision (case selection) for which they would not assume the consequences. Additionally, the original literature, argues in favour of final users' expertise (Ludlow, 1975). We considered that the support committee and the researchers had to have a direct influence on the results of the consultation, since the result expected was a sample of social innovations which need to be meaningful for the field and relevant for researchers in order to conduct the multi-case study. So, each member of the support committee and each participant research centre were asked to choose the five cases they preferred (and wanted to be included in the sample) and to be prepared to justify the reasons for their choice. During a dedicated meeting, members of the support committee and researchers presented their preferred cases and logics for choosing them. At this stage, ordered deliberation was preferred to non-confrontation and anonymization. By doing so, we departed from the core principles of the iterative consultation in the Delphi method, but kept the spirit of broadly defined consensus-based methods (Brady, 2015; Fink, Kosecoff, Chassin, \& Brook, 1984).

The last round aimed to determine the sample composition and similarly included only a restricted pool of experts during a deliberative meeting. 
Table 1: An overview of the Delphi process

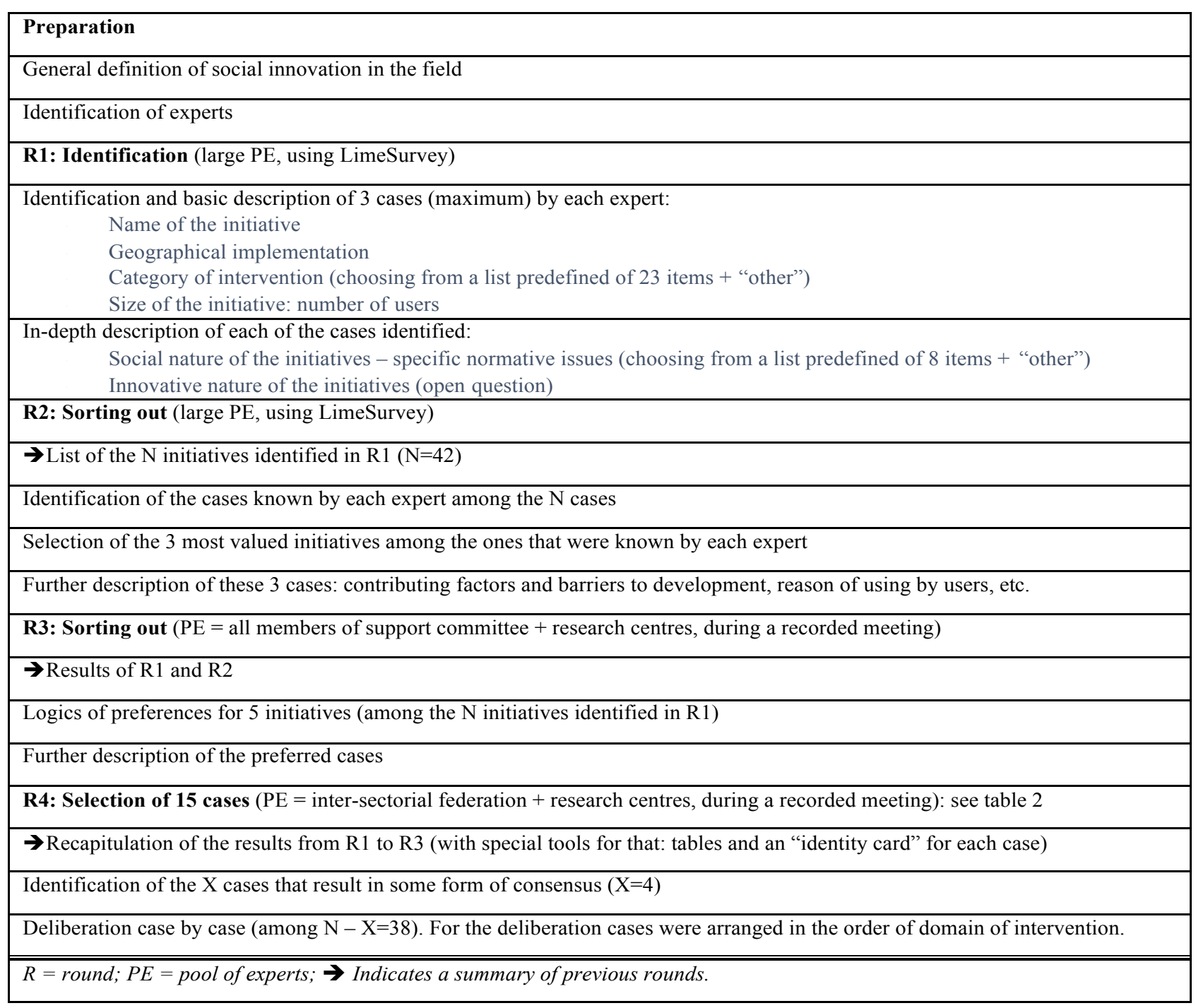

\section{Towards a de-contested sample of social innovations?}

The 42 local social innovations as identified by the Delphi method are very diverse, notably in terms of organizational forms and geographical coverage. The inclusion of rural social innovations appears obvious to us (researchers) since we understand (thanks to the experts) that low density is likely to affect the logics of innovation, and particularly the conception of proximity, which is a basic principle in the organization of eldercare. Our sample thus avoids the urban bias that seems to characterize European innovation studies and policies (da Rosa Pires, Pertoldi, Edwards, \& Barbara Hegyi, 2014). From the point of view of organizational diversity, all cases feature non-profit organisations as full entities, as projects derived from this type of entities or as networks involving them.

Rather than asking for the main activity involved in the suggested social innovation, the questions formulated in the first round allowed for a multi-dimensional description of what situates each case in the field of innovative eldercare provision. It is striking that most cases support family or other close caregivers. No initiative includes core domestic tasks (i.g. cooking and laundry) as an 
area where social innovation occurred. Moreover, only few cases innovate in numerous categories of intervention at the same time. We called them "multidisciplinary approaches". On the basis of the categories of intervention and qualitative data collected during the first round, we were able to build an empirical typology of cases distinguishing six domains of intervention: alternative housing; communitarian approaches; respite eldercare; social support and psychological counselling; multidisciplinary approaches; and technological social innovations. As we will see, the construction of this typology on the basis of an inductive impulse (rather than on pre-defined streams) was instrumental in the sorting out and selection processes.

Two additional results of the first round are worth discussing. Newness as such is not a common feature among all cases. Some have existed for 15 years while the oldest is around 40 . These cases were perceived as remaining in significant ways outside of the institutional arena or as maintaining high innovative organisational capacity across the years. Furthermore, the description of the social nature of mentioned cases refers to the criteria of autonomy and dignity for the involved elderly than to improvements in workers' working conditions. Schultz and colleagues (Schultz et al., 2015) already pointed out the absence of the issue of work in dominant approaches of innovation in the field.

The sorting out of cases was the main purpose of the second and third rounds. In the second round, we evaluated which cases were known and positively valued by the experts. Practically, some cases were well known and highly preferred (rockstar). Others were also well known but more (controversial) or less preferred (controversial+). Additionally, there were less known cases attracting more (discreet) or less preference (invisible).

In the third round (deliberative meeting), the sorting out of cases rested on the assessment of the rationales behind preferences by a second pool of experts (members of the support committee and research teams). We distinguished three distinct but somewhat overlapping logics behind expert preferences: networking; diversification; and theme. Unsurprisingly, the members of the support committee valued cases of social innovation that belonged to their own networks. In other terms, umbrella organizations selected cases among the initiatives they know the better and support. Furthermore, they also deployed a logic of diversification because, as one member said, "Everything is important". Following this logic, the members of the support committee picked-up cases outside what they call their own "machines" and among different domains of intervention. Ageing in place is a complex issue and a number of specific shortcomings need to be addressed. The justification stressed the specific shortcomings each case addresses (for example the deficient supply of respite care for elderly persons living with Alzheimer and their family, the issue of medication adherence, etc.) but also considered matters such as internal democracy (as opposed to bureaucratic structures) and cost-effectiveness. Rationales advanced by the research centres were related to the opportunities each case offered to investigate the themes covered by the research. Cases under consideration ensured a large diversity in terms of resourcing and funding, work environments and approaches of health. Cases that were familiar to the researchers were not excluded per se but we specifically ensured the inclusion of other initiatives.

The aim of the last round was to select the fifteen cases that would form the sample (deliberative meeting including the inter-sectorial federation for non-profit organizations and the research teams). Considering the results of previous rounds, we first observed that four very different cases were approved consensually: a communitarian approach of day care; a respite care initiative for Alzheimer patients and family or other close caregivers; a community primary healthcare centre; and 
a nurse service using an electronic pill dispenser. These four cases were ipso facto included in the sample (see table 2). The remaining eleven cases were selected despite the lack of consensus among experts in previous rounds. Rather, they matched with the idea of a pragmatic agreement based on the respect of a reasonable dissension. We deliberated on each potential case and we took representativeness regarding the previously identified domains of intervention as a compulsory selection criterion.

Table 2: An overview of the sample

\begin{tabular}{|c|c|c|c|}
\hline \multicolumn{4}{|l|}{ Alternative housing } \\
\hline \multicolumn{2}{|c|}{$\begin{array}{l}\text { Intergenerational home-sharing } \\
\text { New organization, urban multi-sites } \\
\text { Rockstar } \\
\text { Outside LN } \\
\text { Outside LD } \\
\text { Householding (domestic resources) } \\
\text { Hybrid funding } \\
\text { New profession (counsellors on home-sharing) }\end{array}$} & \multicolumn{2}{|c|}{$\begin{array}{l}\text { Adapted housing } \\
\text { New rural project } \\
\text { Discreet } \\
\text { Outside LN } \\
\text { Outside LD } \\
\text { Focus on technical (architectural) solutions } \\
\text { The head office is a traditional actor of home care }\end{array}$} \\
\hline \multicolumn{4}{|l|}{ Communitarian approaches } \\
\hline \multicolumn{2}{|c|}{$\begin{array}{l}\text { Communitarian approach of day care } \\
15 \text { years old, rural network, multi-sites } \\
\text { Rockstar } \\
\text { LN } \\
\text { LD } \\
\text { Hybrid funding } \\
\text { New profession (activity leaders for the elderly) } \\
\quad \Rightarrow \text { Relatively high consensus }\end{array}$} & \multicolumn{2}{|c|}{$\begin{array}{l}\text { Provincial platform for the diffusion of knowledge about } \\
\text { Alzheimer } \\
\text { New rural network } \\
\text { Controversial+ } \\
\text { Outside LN } \\
\text { Outside LD } \\
\text { Public provincial funding }\end{array}$} \\
\hline \multicolumn{4}{|l|}{ Respite care } \\
\hline \multicolumn{2}{|c|}{$\begin{array}{l}\text { Respite care Alzheimer } \\
\text { New project, urban and rural } \\
\text { Controversial } \\
\text { LN } \\
\text { LD } \\
\text { Public regional funding } \\
\text { New profession (home caregivers specialized in Alzheimer) } \\
\quad \Rightarrow \text { Relatively high consensus }\end{array}$} & \multicolumn{2}{|c|}{$\begin{array}{l}\text { Continuous respite care (packages for } 3 \text { days) } \\
\text { New rural project } \\
\text { Rockstar } \\
\text { LN } \\
\text { Outside LD } \\
\text { Public federal funding (cost-efficiency under test) }\end{array}$} \\
\hline \multicolumn{4}{|c|}{ Social support and psychological counselling } \\
\hline $\begin{array}{l}\text { Psychological counselling Alzheimer } \\
\text { New urban project } \\
\text { Rockstar } \\
\text { Outside LN } \\
\text { Outside LD } \\
\text { Free service } \\
\text { Project lead by a small organization }\end{array}$ & \multicolumn{2}{|c|}{$\begin{array}{l}\text { Domiciliary social support } \\
\text { New urban project } \\
\text { Discreet } \\
\text { LN } \\
\text { Outside LD } \\
\text { Voluntary workers (only) } \\
\text { Free service } \\
\text { Project lead by a mutual health } \\
\text { insurance }\end{array}$} & $\begin{array}{l}\text { Domiciliary psychological support } \\
\text { New urban project } \\
\text { Discreet } \\
\text { Outside LN } \\
\text { Outside LD } \\
\text { Public federal finding (cost-efficiency under } \\
\text { test) }\end{array}$ \\
\hline \multicolumn{4}{|l|}{ Multidisciplinary approaches } \\
\hline $\begin{array}{l}\text { Community primary healthcare centre } \\
\text { Old urban organization } \\
\text { Discreet } \\
\text { LN } \\
\text { LD } \\
\text { Self-governance } \\
\text { Free or accessible service } \\
\text { Public federal funding (capitation) } \\
\quad \Rightarrow \text { Relatively high consensus }\end{array}$ & \multicolumn{2}{|c|}{$\begin{array}{l}\text { Domiciliary hospitalisation } \\
\text { New urban project } \\
\text { Rockstar } \\
\text { LN } \\
\text { Ambulatory healthcare } \\
\text { Cost-effectiveness (discourse on) }\end{array}$} & $\begin{array}{l}\text { Domiciliary multidisciplinary geriatric } \\
\text { team } \\
\text { New urban project } \\
\text { Discreet } \\
\text { LN } \\
\text { LD } \\
\text { Public federal finding (cost-efficiency under } \\
\text { test) }\end{array}$ \\
\hline
\end{tabular}




\begin{tabular}{|l|l|}
\hline \multicolumn{2}{|l|}{ Alternative housing } \\
Technologically lead social innovations
\end{tabular}

\section{Conclusion}

Is there a need for specific methodologies in social innovation research? Our aim was to demonstrate that the essentially contested character of the social innovation concept entails methodological challenges, particularly at the stage of sampling. In this article we showed that the Delphi method can be adapted and implemented in order to address, at this very important first stage of the research, the strong ambiguity of social innovation.

We believe that decontestation - i.e. the search for conceptual clarification has much to do with producing transdisciplinary knowledge strengthened by meaningful examples. In this article we proposed a comprehensive and inductive sampling procedure based on experts' perceptions of what constitutes social innovation in domiciliary eldercare. Rather than considering cases a priori aligned with the "weak" versus "strong" approach of social innovation, we chose to capture contestedness in the field.

Concretely, the Delphi method and its principles of expertise, consensus and iterative consultation, were adjusted to select a final sample of 15 cases chosen out of a set of 42 potential cases. Selected cases represent domains of intervention empirically identified as relevant for the field. They also represent geographical and organisational diversity. Our procedure questions: specific normative issues (round 1); general positive valuation conditional on knowledge (round 2); and logics of preferences (including researchers' preferences) (round 3). These different rounds shed light on how the field of domiciliary eldercare arranges its conceptions of social innovation. Certainly, one can ex-post associate some cases of the sample with some kind of "weak" approach and others with a more transformative one. However, both approaches can be found among the consensual cases. Moreover, any attempt go in depth into the analysis of change in the field through the lenses of social innovation necessitates the inclusion of more balanced and atypical cases.

Thanks to the developed methodological approach, we sampled cases with which we were not initially familiar. In that sense, we significantly enlarged our understanding of the field. The sample acknowledges networking by the support committee, but is not limited to it. The sample includes cases engendered by historical actors but by also newcomers in the field. Therefore, we were able to avoid producing "a parade of successful innovations" (Larsson \& Brandsen, 2016, p. 299).

Besides, the high response rate in the first and second rounds, the commitment of the support committee members in further rounds, and the feasibility of the study for 14 out of the 15 cases are some of the indicators pointing to the internal validity of the method. 
The method has its limits though. First, it appeared that the characterization of cases provided to the experts in the third round was somehow insufficient. A deeper characterization would be likely to strengthen the logic of diversification and hence also strengthen the consensus. More generally, the summaries we are able to provide to the experts influence the final outcome. Second, this method is time-consuming: nearly seven months elapsed since the preparation of the first round and the selection. Moreover, the method requires a high reactivity in terms of analysis, since each new round is based on the synthesis of the results of the previous round. Although this phase was also generating data and knowledge about social innovation in the field, seven months is a long time in the course of a 30-month research project. Admitting that (time) constraints in research, raises the question of who is funding social innovation research and under what (time) conditions. Do we have the adequate means to properly implement a consensus-based procedure of "sampling" social innovations before conducting in-depth case studies? If the answer to that question is negative, then it is urgent to advocate for less constraining research programmes that allow researchers to really devote time and energy to sampling and by doing so, to contribute to a less cleaved scientific debate.

\section{References}

Ayob, N., Teasdale, S., \& Fagan, K. (2016). How Social Innovation "Came to Be": Tracing the Evolution of a Contested Concept. Journal of Social Policy, 45(4), 635-653.

Baker, J., Lovell, K., \& Harris, N. (2006). How expert are the experts? An exploration of the concept of "expert" within Delphi panel techniques. Nurse Researcher, 14(1), 59-70.

Booto Ekionea, J.-P., \& Bernard, P. (2011). Consensus par la méthode Delphi sur les concepts clés des capacités organisationnelles spécifiques de la gestion des connaissances. Recherches Qualitatives, 2011(29), 168-192.

Bouchard, M. J., Trudelle, C., Briand, L., Klein, J.-L., Lévesque, B., Longtin, D., \& Pelletie, M. (2015). A Relational Database to Understand Social Innovation and Its Impact on Social Transformation. In A. Nicholls, J. Caulier-Grice, \& M. Gabriel (Eds.), New Frontiers in Social Innovation Research (pp. 69-85). Palgrave Macmillan UK.

Bourrée, F., Michel, P., \& Salmi, L. R. (2008). Méthodes de consensus: revue des méthodes originales et de leurs grandes variantes utilisées en santé publique. Revue d'Epidemiologie et de Sante Publique, 56(6), 415-423.

Brady, S. R. (2015). Utilizing and Adapting the Delphi Method for Use in Qualitative Research. International Journal of Qualitative Methods, 14(5), 1-6.

Byrne, E., Mullally, G., \& Sage, C. (Eds.). (2016). Transdisciplinary Perspectives on Transitions to Sustainability. Routledge.

Collier, D., Hidalgo, F. D., \& Maciuceanu, A. O. (2006). Essentially contested concepts: Debates and applications. Journal of Political Ideologies, 11(3), 211-246.

da Rosa Pires, A., Pertoldi, M., Edwards, J., \& Barbara Hegyi, F. (2014). Smart Specialisation and Innovation in Rural Areas. JRC (Joint Research Centre of the European Commission) Technical Reports.

Dalkey, N. (1969). The Delphi Method: An Experimental Study of Group Opinion. The RAND Corporation. Santa Monica.

Evers, A., \& Brandsen, T. (2016). Social Innovations as Messages: Democratic Experimentation in Local Welfare Systems. In T. Brandsen, S. Cattacin, A. Evers, \& A. Zimmer (Eds.), Social Innovations in the Urban context (p. 313). Springer Open.

Evers, A., Ewert, B., \& Brandsen, T. (2014). Social innovations for social cohesion. Transational patterns and approaches from 20 European cities. Liege: EMES European Research Network.

Fink, A., Kosecoff, J., Chassin, M., \& Brook, R. H. (1984). Consensus methods: Characteristics and 
guidelines for use. American Journal of Public Health, 74(9), 979-983.

Flyvbjerg, B. (2006). Five Misunderstandings About Case-Study Research. Qualitative Inquiry, 12(2), 219-245.

Fougère, M., Segercrantz, B., \& Seeck, H. (2017). A critical reading of the European Union's social innovation policy discourse:(Re) legitimizing neoliberalism. Organization, 24(6) 819-843. Gallie,

W. B. (1956). Essentially Contested Concepts. Proceedings of the Aristotelian Society, 56, 167198.

Giraud, O., Lucas, B., Falk, K., Kümpers, S., \& Lechevalier, A. (2014). Innovations in Local Domiciliary Long-Term Care: From Libertarian Criticism to Normalisation. Social Policy and Society, 13(3), 433-444.

Goodman, C. (1987). The Delphi technique: a critique. Journal of Advanced Nursing, 12(6), 729734.

Goodman, C. (2017). Conversation or consensus: Using the Delphi technique to set priorities for ageing research and practice. Age and Ageing, 46(1), 6-7.

Hamel, J. (1997). Étude de cas et sciences sociales. Montréal-Paris: L'HARMATTAN.

Landeta, J., Barrutia, J., \& Lertxundi, A. (2011). Hybrid Delphi: A methodology to facilitate contribution from experts in professional contexts. Technological Forecasting and Social Change, 78(9), 1629-1641.

Larsson, O. S., \& Brandsen, T. (2016). The Implicit Normative Assumptions of Social Innovation Research: Embracing the Dark Side. In T. Brandsen, S. Cattacin, A. Evers, \& A. Zimmer (Eds.), Social Innovations in the Urban context (pp. 293-302). Springer Open.

Linstone, H. A., \& Turoff, M. (1975). Delphi Method: Techniques and Applications. Boston: Addison-Wesley.

McKenna, H. P. (1994). The Delphi technique: a worthwhile research approach for nursing? Journal of Advanced Nursing, 19(6), 1221-1225.

Montgomery, T. (2016). Are Social Innovation Paradigms Incommensurable? VOLUNTAS: International Journal of Voluntary and Nonprofit Organizations, 27(4), 1979-2000.

Moulaert, F. (2009). Social Innovation: Institutionally Embedded, Territorially (Re)Produced. In D. MacCallum, F. Moulaert, J. Hillier, \& S. Vicari Haddock (Eds.), Social Innovation and Territorial Development (pp. 11-23). Farnham, England \& Burlington, USA: ASHGATE. Murphy, M., Black, N., Lamping, D., McKee, C., Sanderson, C. F. ., Askham, J., \& Marteau, T. (1998). Consensus development methods and their use in clinical guideline development. Health Technology Assessment, 2(3), i-iv.

Murray, R., Caulier-Grice, J., \& Mulgan, G. (2010). The Open Book of Social Innovation. The Young Foundation \& NESTA (National Endowment for Science, Technology and the Arts).

Nagaoka, S., Motohashi, K., \& Goto, A. (2010). Patent statistics as an innovation indicator. In Handbook of the Economics of Innovation (Vol. 2, pp. 1083-1127).

Nyssens, M. (2015). Innovation sociale et entreprise sociale: quels dialogues possibles? Une perspective européenne. In A. Camus, C. Jetté, J.-L. Klein, \& M. Roy (Eds.), La transformation sociale par l'innovation sociale (pp. 335-348). Québec: Presses de l'Université du Québec.

Pol, E., \& Ville, S. (2009). Social innovation: Buzz word or enduring term? Journal of SocioEconomics, 38(6), 878-885. https://doi.org/10.1016/j.socec.2009.02.011

Popa, F., Guillermin, M., \& Dedeurwaerdere, T. (2015). A pragmatist approach to transdisciplinarity in sustainability research: From complex systems theory to reflexive science. Futures, 65, 4556. https://doi.org/10.1016/j.futures.2014.02.002 
Rialle, V. (2015). Quelle autonomie peut apporter la technologie1? De l'aide à la personne âgée à la naissance d'une nouvelle société. Ethics, Medicine and Public Health, 1(2), 155162. https://doi.org/10.1016/j.jemep.2015.03.008

Rowe, G., \& Wright, G. (1991). The Delphi Technique: a Re-Evaluation of Research and Theory. Technological Forecasting and Social Change, 39(January 2015), 235-251.

Schultz, J. S., André, B., \& Sjøvold, E. (2015). Demystifying eldercare: Managing and innovating from a public-entity's perspective. International Journal of Healthcare Management, 8(1), 4257.

Seawright, J., \& Gerring, J. (2008). Case Selection Techniques in Case Study Research: A Menu of Qualitative and Quantitative Options. Political Research Quarterly, 61(2), 294-308. https://doi.org/10.1177/1065912907313077

Stake, R. E. (2006). Multiple case study analysis. New York: Guilford Press.

Tapio, P., Paloniemi, R., Varho, V., \& Vinnari, M. (2011). The unholy marriage? Integrating qualitative and quantitative information in Delphi processes. Technological Forecasting and Social Change, 78(9), 1616-1628.

Wittmayer, J. M., Backhaus, J., Avelino, F., Pel, B., Strasser, T., \& Kunze, I. (2015). Narratives of change: How Social Innovation Initiatives engage with their transformative ambitions (No. 4). TRANSIT Working Paper. 